\title{
La búsqueda de coordenadas para una historiografía materialista
}

\section{Searching for coordinates of a materialist historiography}

\section{Luciano Alonso \\ lpjalonso8@gmail.com \\ Universidad Nacional del Litoral, Argentina}

Cita sugerida: Alonso, L. (2021). La búsqueda de coordenadas para una historiografía materialista. Sociohistórica, 47, e125. https://doi.org/10.24215/18521606e125
Resumen: El presente texto muestra las principales opciones teóricas y metodológicas con las cuales el autor ha trabajado temas como los procesos represivos en la historia del presente, las luchas por los derechos humanos o la intersección entre cultura y política en la historia argentina "reciente". El ensayo parte de un posicionamiento respecto del enfoque general y la concepción de lo social, teniendo como objetivo una visión renovada del materialismo histórico y cultural. Luego se justifica la preferencia por un pluralismo metodológico, en función de la primacía del objeto de estudio por sobre las tradiciones de las distintas disciplinas. A partir de ese aspecto se va pasando por diversas cuestiones teórico-metodológicas tratadas en la reunión científica para la cual fue escrito el texto. La intención general es la de proponer una hibridación teórica y una historiografía que no caiga en narrativas esquemáticas o solipsistas.

Palabras clave: Historiografía Materialista, Hibridación Teórica, Pluralismo Metodológico y Conceptual.

Abstract: This text shows the main theoretical and methodological options with which the author has worked on topics such as the repressive processes in the history of the present, the struggles for human rights or the intersection between culture and politics in "recent" Argentine history. The essay begins with a position regarding the general approach and the conception of the social, bearing in mind a renewed vision of historical and cultural materialism. Then the preference for a methodological pluralism is justified, based on the primacy of the object of study over the traditions of the different disciplines. From this aspect, different theoretical-methodological questions are discussed at the scientific meeting for which the text was written. The general intention is to propose a theoretical hybridization and a historiography that does not fall into schematic or solipsistic narratives.

Keywords: Materialistic Historiography, Theoretical Hybridization, Methodological and Conceptual Pluralism.

\section{DeFINICIONES BÁSICAS}

Es sabido que, dentro de su genialidad y aun considerando su magna obra, en ocasiones Karl Marx no tenía 
buenas ideas. Probablemente su peor falla fue la de no encontrar un sustituto para la palabra materialismo al momento de poner en claro su propio enfoque y redactar las justificadamente famosas Tesis sobre Feuerbach (Marx, 1993). De ahí esa situación paradójica en la que unas notas esclarecedoras, que presentaron la ruptura de la dicotomía sujeto-objeto en el proceso de producción del conocimiento y una alternativa superadora a las estrategias gnoseológicas del idealismo y del materialismo contemplativo, abogaran simplemente por un "nuevo materialismo". El mismo Marx y junto con él o por separado Friedrich Engels intentaron esclarecer su "concepción materialista de la historia" (Engels, 2000, Sección III), pero la confusión estaba servida -incluso a veces para ellos mismos-. Muy frecuentemente se podía embrollar el "materialismo" con "las cosas" o lo material en sentido estricto, cuando notoriamente Marx se alejaba de toda definición sustancialista o cosificadora y desarrollaba una concepción relacional de lo social y de su dinámica. Sería en ese punto donde se encontraría otro de sus grandes aportes: la noción de que las categorías científicas -creadas a partir de la percepción de lo concreto y de los procesos de abstraccióndeben intentar dar cuenta de las relaciones sociales en el movimiento de lo concreto (Marx, 1972).

Pasada demasiada agua debajo de los puentes desde aquel momento seminal de la moderna teoría social, ${ }^{1}$ podríamos decir que debemos superar constantemente las encerronas de las dicotomías y reformular nuestra concepción de lo social como objeto de estudio. Mi opción personal, en ese caso, se decanta por la propuesta de William Sewell Jr. según la cual lo social puede ser concebido como una red articulada y cambiante de prácticas semióticas - no sólo lingüísticas- que construye y transforma los marcos materiales, marcos que a su vez constituyen entornos construidos que establecen las matrices de aquellas prácticas y que delimitan sus consecuencias (Sewell, 2006). Y así como Sewell puede pretender que esa concepción sincrética representa la posibilidad de que lo social continúe siendo considerado dentro del amplio marco epistemológico establecido por el giro lingüístico, de mi parte podría esperar que los fenómenos semióticos puedan ser adecuadamente inscriptos en una concepción materialista de la historia.

Tal vez esa sea la enésima posibilidad de pensar un "materialismo cultural" o fórmula de circunstancia similar, inserto por las buenas o las malas en la tradición del materialismo histórico con todo lo que este conlleva de indivisión disciplinar. ${ }^{2}$ Como sea, la referencia canónica a Marx y a la tradición inaugurada por él puede ser absolutamente superflua hoy en día, aunque hayamos incorporado casi inconscientemente muchos de sus planteos o nociones. ${ }^{3}$ No serían imprescindibles para desplegar nuestras estrategias investigativas o nuestra concepción de lo social. Pero con seguridad que sus menciones no dejan de tener efectos políticos y por ello siguen valiendo la pena.

Teniendo en cuenta estas proposiciones fundamentales, ¿̇cómo se podría desplegar una historiografía "materialista" en la actualidad, sabiendo que lo "material" en el sentido de lo "realmente existente" supone no solo relaciones sociales y entornos construidos sino también un complejo inextricable de prácticas semióticas? De mi parte, una doble incapacidad para mantener separadas tradiciones y jergas disciplinares por un lado, y para construir una epistemología de base suficientemente desarrollada por el otro, me ha llevado a cierto pragmatismo. El conversatorio sobre "Usos de la historia...", coordinado por Victoria Haidar, Mariela Rubinzal y Laura Schenquer el 4 de diciembre de 2018 en la Universidad Nacional del Litoral, actuó quizás como un acicate para poner en papel una reseña (incompleta) de aquellos elementos que sustentan mi labor investigativa -por lo demás muy clásicos y plenos de trasvases facilitados por la docencia universitaria en

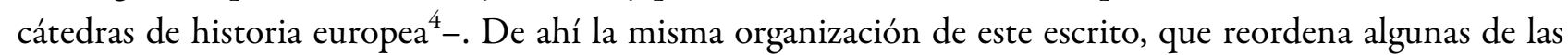
cuestiones tratadas en ese encuentro y tiene inevitablemente un marcado tono autorreferencial.

Lo que sigue es entonces un racconto o incluso quizás una racionalización a posteriori de una serie de elecciones que han guiado mi producción ¿historiográfica?, ¿sociológica?, ¿diletante? Seguramente la exposición de mis propias opciones muestra simplemente la deriva constante a través de la cual he tratado de sostener aproximaciones siempre incompletas al conocimiento de los procesos represivos, las luchas por los derechos humanos o la intersección entre cultura y política en la historia argentina "reciente". 5 Pero quisiera creer que tantas líneas de reflexión sobre los modos de hacer historia del presente se intersectan en algunos 
puntos definidos de mi propia producción historiográfica, a la manera de coordenadas que sostienen una concepción de lo social y tratan de acercarse al conocimiento de algunos de sus aspectos.

\section{MÉtodos}

Nunca he sido muy bueno en el seguimiento de una metodología determinada y menos aún en la definición de una única metodología propia. He justificado esa imposibilidad personal con el apego a tres criterios que obligarían a trabajar con metodologías plurales:

a) Siguiendo a Paul Ricoeur (1991, caps. 2 y 4), es muy discutible que se pueda separar tajantemente una metodología de una teoría porque ambas dimensiones estarían mutuamente implicadas. Ahora bien, si como lo postula Anthony Giddens (1995, Introducción) no hay ninguna teoría que pueda dar cuenta acabadamente de lo social y el horizonte con el que nos manejamos es el de utilización conjunta, articulación o hibridación de distintas teorías (cualquiera sea el caso), entonces eso mismo se seguiría respecto de las metodologías. Una variante de este criterio es la que indica que no habría una distinción clara entre - por ejemplo- métodos históricos y sociológicos, que están derivados mayormente de tradiciones disciplinares diferentes más que de propuestas teóricamente contrastadas, y que entonces sería deseable articular metodologías de distinta adscripción disciplinar.

b) Si para evitar el solipsismo intelectual o el idealismo liso y llano es conveniente diseñar estrategias que resulten apropiadas para el abordaje del objeto de estudio (obviamente sabiendo que el objeto se produce en un proceso de formulación de problemas guiado por los marcos teóricos, las posibilidades de trabajo académico y las implicancias ideológicas de quien lo define), entonces estrictamente no podría aplicarse la misma metodología a dos objetos de estudio diversos (y salvo simplificación absurda o planteo globalizante no hay dos objetos de estudio iguales aunque sea por cuestiones de ubicación espacio-temporal). A esto creo que es a lo que alude Immanuel Wallerstein cuando refiere a la primacía del objeto de estudio por sobre las tradiciones disciplinares, y por ende por sobre las metodologías consagradas en una u otra de ellas (Wallerstein, 1998).

c) Si el conocimiento sobre el pasado tiene límites evidentes - no solo por la imposibilidad fáctica de restituir lo desaparecido o por la falta de fuentes que nos permitan abordar en su completitud un objeto, sino también muy especialmente por la distancia de sentido que hay entre los diversos agrupamientos humanos y nuestros propios marcos interpretativos-, entonces hay que tratar de forzar todo lo posible las metodologías de las que disponemos para acrecentar nuestro margen de conocimiento, aunque en el extremo ni siquiera se produzca un conocimiento certero sino tan solo una especulación razonada.

Podría decirse que todo lo anterior es simplemente un conjunto de enunciados justificatorios que llevarían a una suerte de anarquismo epistemológico, pero estoy convencido de que si algo diferencia a las disciplinas científicas de cualquier otra forma de conocimiento sobre lo social es precisamente el seguimiento de métodos constantemente contrastables. En consecuencia, podría decir que globalmente me apego a algunos métodos generales, aplicando técnicas específicas subordinadas a esos grandes constructos.

El primero sería un método histórico-crítico (a veces histórico-comparativo), asentado en la interpretación de fenómenos (podríamos decir, una variante de la fenomenología). Algunos de los recursos que aplico bajo este método general remiten en rigor a formas consagradas en metodologías más específicas. Así, recurro en ocasiones a la búsqueda de indicios, a la contrastación entre visiones emic y etic, a la articulación entre inferencia documental e inferencia lógica o al análisis de situaciones ubicadas en un escenario. Esas cuatro estrategias pueden ser referidas a las influencias de autores como Carlo Ginzburg (1989 y 2007), Marvin Harris (1998), Natalie Zemon Davis (1984 y 2013) y Edward P. Thompson (2000), respectivamente. Para las operaciones comparativas, asumo habitualmente a las formas de trabajo propuestas por Charles Tilly, lo que supone estrategias con cuatro posibles objetivos: individualizar, diferenciar, universalizar o globalizar 
(Tilly, 1991). Obviamente, el mismo recurso a la comparación puede ser pensado a su vez bajo la definición de un método.

Pero también, en función de las limitaciones del método histórico-crítico y de la necesidad de articular niveles y dimensiones de análisis variados, he recurrido a formas hipotético-deductivas. Ello ha sido evidente cuando he tratado de establecer correlaciones entre un nivel espacial general y uno particular (o una historia general y una historia particular). Para ello me he servido de los modos de análisis -que no de producción de datos- de la teoría de los sistemas mundo y en especial de los aportes de Wallerstein (v. g. 1998 y 2008). Concedo la validez del planteo de Siegfried Kracauer según el cual es muy difícil articular historias particulares e historia general, al tiempo que la segunda tiene un componente estético muy grande (2010, cap. 7). Pero al mismo tiempo opino que una teoría de lo macro construida mediante la referencia constante a lo empírico y que de hecho sólo puede renovarse por contrastación empírica y consecuente generalización (véase Hung, 2019) - da posibilidades de forjar narraciones explicativas más amplias aunque no se encuentre una evidencia clara de articulación entre lo particular y lo general.

Como es evidente esas dos tendencias metodológicas (método histórico-crítico y método hipotéticodeductivo) son las que coexisten con diversa suerte en la obra de Karl Marx, al tiempo que esa doble vía de conocimiento no me parece necesariamente contradictoria sino que estimo que puede ser complementaria. El lugar categorial de articulación es la noción de totalidad, otra vez referenciada al apartado sobre el método de la Introducción generala la critica de la economía política (Marx, 1972). Eso no supone el apego a un conocimiento mistificado o a la imposible noción de una "historia total", sino a la propuesta de un método progresivo / regresivo con su lógica de totalización / destotalización / retotalización permanente, que puede encontrarse en los aportes de Jean-Paul Sartre y para nuestro medio en Eduardo Grüner (2006). ${ }^{6}$

En la actualidad, los planteos de William Sewell Jr. me parecen superadores de las antinomias tradicionales y capaces de fundar trabajos en los que se articulen dimensiones y miradas tan variadas como las expuestas. No solo su noción de reformulación de lo social permite comprender una fructífera relación entre lenguaje y materialidad, discursos y prácticas, sino que también tienen principal importancia su revisión del concepto sociológico de estructura; la articulación entre acontecimiento y estructura o la ponderación de las posibilidades de la totalización (Sewell, 2005).

Probablemente no haya logrado en ninguna de mis investigaciones una articulación como la que me propongo y todas sean aproximaciones de diverso grado en función de distintos problemas. Algunos trabajos en los que expresamente he intentado estas combinaciones son aquellos dedicados al movimiento por los derechos humanos (Alonso, 2011), al cotejo de los regímenes represivos y de violencia de dictaduras iberoamericanas (Alonso, 2013), a la definición de las violencias de Estado respecto de la última dictadura argentina (Alonso, 2014a) o al estudio de la articulación entre cultura y política en la transición a la democracia (Alonso, 2017 y 2019a).

Ese pluralismo metodológico supone distintas formas de organización del material y de producción de datos, adecuadas no sólo a las exigencias de una u otra técnica sino también al momento de la producción, a la disponibilidad de fuentes y -por qué no- a la etapa o la situación de mi vida laboral o personal. En general clasifico las fuentes por tipo siguiendo distintos criterios: periodísticas, iconográficas, orales, por tipo de documento, etcétera. Muchas veces el registro se hace en un repositorio u otro, así que suelo reproducir esa clasificación respecto de cada uno de ellos.

La selección de textos se rige por dos criterios básicos: a) lo relacionado apriorísticamente con la temática que quiero abordar y b) lo que emerge como "descubrimiento" en el archivo. Este segundo criterio depende a su vez de una mezcla de interés y oficio (más del primero que del segundo) y de la idea defendida por autores como Carlo Ginzburg o Edward Thompson en el sentido de que la producción de datos no debe estar prefijada, sino que debe también haber una apertura mental al impacto que el archivo pueda tener sobre la investigación en tanto aparición de lo inesperado. 
A su vez, en la producción de fuentes orales he realizado la selección de entrevistadas y entrevistados por muestreo y por encadenamiento o bola de nieve, y en la observación participante u observación a secas he alternado registros con protocolo con registros aleatorios o azarosos (por ejemplo, al identificar un problema relativo a memorias sociales en la visita a un museo o al descubrir una forma expresiva particularmente descollante en una manifestación). Para la producción de fuentes orales me guío por las recomendaciones de Alessandro Portelli (2004) y su inmensa capacidad para hacer simple y efectivo un tema tan complejo. No desgrabo las entrevistas y tomo notas escuchando los silencios, inflexiones o variaciones de las voces, aunque muchas veces al cotejar entrevistas sobre una misma cuestión me veo en la obligación de tratarlas como cualquier otra fuente y registrar por escrito la información que brindan sobre distintos aspectos, para poder comparar cada ítem con posterioridad.

En el análisis de cualquier texto y en todo momento me guío por la máxima de Gregory House: " "todo el mundo miente". No en el sentido literal sino en tanto toda producción de un enunciado se encuentra condicionada por los límites conscientes e inconscientes del enunciador o la enunciadora. Ergo, los textos no son jamás transparentes y allí se encuentra la parte más interpretativa y "crítica” del método, aunque el concepto de crítica no sólo tiene la connotación de develamiento de lo que está oculto tras lo visible, sino también de vínculo del conocimiento con las luchas y anhelos de una época (Marx, 2014).

\section{CATEgorías y CONCEPTOS}

Mis trabajos versan de una u otra manera sobre la dialéctica entre dominación y resistencia. Quizás eso se deba a mi apego al "paradigma de la dominación" de autores como Marx o Bourdieu, según el cual las sociedades son constitutivamente inequitativas y existen mecanismos estructurales y dispositivos estratégicos de reproducción de la desigualdad. Obviamente, estos conceptos no pueden ser aplicados sin más a cualquier materia, pero aunque sea como categorías básicas o subyacentes organizan la pesquisa, el análisis y la exposición de temas tan distintos como la represión, la movilización social, la producción artístico-literaria, etcétera. Entiendo dominación como una forma de poder sistemáticamente asimétrico (Thompson, 1987), que en el extremo supone la anulación de toda resistencia o posibilidad de contestación (Foucault, 2007, p. 200). La resistencia es fundamentalmente para mí contrapoder, un concepto más propio de Toni Negri (2001) pero que me parece iluminador por sus implicancias. En última instancia, dominación y resistencia son como puntos extremos entre los cuales corre la mayor parte de las relaciones de poder, que casi nunca se encuadran en uno o en otro término de manera completa.

Puede advertirse que la categoría dominación se abre a una serie de conceptos asociados de uso frecuente como ser poder, control social, dispositivos de poder o de control, reproducción y similares, en tanto que resistencia supone otras conceptuaciones emparentadas pero bien distinguibles como disidencia, oposición, desviación o en el extremo innovación o poder constituyente. A su vez la relación dialéctica entre términos como los citados supone procesos de acción contenciosa, interacción, distinción o directamente lucha o puja. Ese universo conceptual permite la identificación de escenarios o teatros en los cuales transcurre la acción. En general me remito a aportes conceptuales que corresponden en parte a las teorías de la dominación (Pierre Bourdieu, Michel Foucault), a la historia social (Edward Palmer Thompson, Raphael Samuel, William Sewell, Natalie Zemon Davis), a las teorías de la movilización social (Charles Tilly, Sidney Tarrow, Dough McAdam) y a la teoría de los sistemas-mundo (Immanuel Wallerstein, Peter Taylor). En el fondo, los marcos categoriales no me parecen "cerrados" sino combinables en función del objeto de estudio. En mis últimos trabajos, por ejemplo, he debido recurrir a categorías provenientes del campo de los estudios culturales o artístico-literarios, con aportes de Peter Bürger, Hans Robert Jauss, Walter Benjamin, Terry Eagleton, Fredric Jameson, Stuart Hall y un largo etcétera.

Inevitablemente, el vocabulario del análisis social tiene que dar cuenta de alguna manera de los límites interiores a cada sociedad. Cada categoría social simultáneamente aglutina agentes juzgados semejantes, 
escinde conjuntos de agentes considerados desemejantes y define relaciones entre ambos (Tilly, 2000, p. 75). Y esa categorización supone la atención a las definiciones emic pero también una tarea de delimitación etic de las fronteras sociales. Al respecto, categorías como clase o género (y sexo) han tenido una aparición muy disímil en mis distintos trabajos. En general, tienen una escasa presencia pero son parte del subtexto que sostiene la argumentación. Con Robert Lane Fox (2009, p. 225), pienso que el sexo y la clase social son las constantes de todos los seres humanos.

El estudio de la situación de clase me parece imprescindible aun cuando no realice análisis de clase. Por ejemplo, respecto de la movilización pro derechos humanos me interesa destacar que se trata de movimientos sociales que no se construyen con una identidad o definición clasista, que tienen una composición policlasista y que no responden a intereses de clase, pero que sólo son posibles gracias a los insumos culturales provistos por determinadas situaciones de clase (Alonso, 2019b). También entiendo al género como una relación social básica, a veces solapando esa noción con la de sexo, suponiendo que la segunda no puede remitirse jamás al plano de lo biológico. En los escasos trabajos que he realizado sobre sociología histórica del período tempranomoderno, inspirados por mi desempeño docente, la categoría sexo/género ha sido esencial (v.g. Alonso, 1999). Paralelamente, tiendo a observar en mis textos sobre historia del presente y a promover en los de mis dirigidas y dirigidos la consideración del papel de las mujeres, sin que eso suponga una teoría de género, que solo es seguida por algunas y algunos.

La combinación de esas perspectivas me parece imprescindible para explicar desde fenómenos amplios en una macronarrativa de lo social, hasta trayectorias individuales. Por ejemplo, el proceso de educación sentimental por el cual puede constituirse una subjetividad disidente me parece inentendible sin el recurso a perspectivas que iluminen la situación, las restricciones y posibilidades de acción de los agentes en relaciones de clase y género históricas (Alonso, 2018b). Inversamente, no he tenido en general en cuenta la perspectiva étnica ni las categorías a ella asociadas. Quizás tan solo en tanto noción emic a propósito de trabajos que involucran la autopercepción de habitantes de la "pampa gringa" o similares, y hace mucho tiempo (Alonso y Vega, 2000).

Ahora bien, tanto en relación con los conceptos aludidos como en el uso de muchos otros aplico dos criterios que pueden ser polémicos pero que me parecen fructíferos:

a) Cierto pluralismo conceptual. Si es correcto que el lenguaje es nuestro modo de apropiarnos del mundo, no lo es menos que cualquier lengua es una conspiración contra la experiencia que tiende a simplificarla (Baxandall, 2010) y que hay regiones enteras de lo histórico-social que no son reductibles al lenguaje (Sewell, 2006). En consecuencia, nunca un único concepto puede dar cuenta de la diversidad de lo real, sino tan solo del recorte, el enfoque y el ordenamiento que el mismo concepto propone. Si eso es así, distintos conceptos pueden tener aplicaciones diferentes para dar cuenta de diversas facetas o interpretaciones de un objeto. Por ejemplo, soy de los que piensan que puede hablarse de terror o terrorismo de Estado, represión, exterminio planificado o politicidio para referir al proceso experimentado en Argentina entre 1974 y 1980, y que ninguno de esos términos agota los sentidos y potencialidades de todos los otros.

b) Una cierta torsión de los conceptos tomados de otros autores. Al intentar recuperar un concepto determinado que me parece útil para mis trabajos, lo inserto en un campo semántico diferente de aquel en el cual se presentó originalmente. Incluso tratando de respetar los sentidos del término original, su articulación significativa cambia en virtud de una nueva constelación conceptual. En consecuencia, suelo hacer explícita esa torsión al punto que en ocasiones se puede pensar lícitamente que se trata de otro concepto (o en el extremo de otra teoría, dada la articulación propuesta entre distintos conceptos). Es el caso en mis trabajos de gubernamentalidad, una categoría ya variable en Michel Foucault y que ha dado lugar a una profusa bibliografía sobre los modos de ejercicio del poder.

De hecho, creo que en mis propios textos es raro que un concepto se mantenga invariable. Es evidentemente el caso de movimiento social, al que le doy diversas connotaciones para adecuarlo a la experiencia histórica. En los últimos tiempos y a partir de polémicas verdaderamente estériles en las que me 
he visto envuelto, respecto de si tal proceso sociohistórico debe ser nombrado con tal palabra o con tal otra, he tratado de esclarecer mi posicionamiento al respecto (Alonso, 2019c).

\section{TIEMPOS Y ESPACIOS}

Los criterios de definición de las temporalidades y espacialidades son elementos básicos de cualquier investigación sociohistórica, pero su construcción supone la necesidad de desnaturalizar esas variables. Es decir, de reprimir el impulso acrítico de confiar en los almanaques y los mapas. Dado que ni los efectos ni las percepciones del tiempo son homogéneos, me parece imprescindible trabajar con:

a) Temporalidades superpuestas o imbricadas. Las distintas dimensiones sociales o niveles espaciales tienen tiempos diversos. Ejemplo de superposición: la temporalidad de los ciclos de movilización en el sistema mundial, del movimiento por los derechos humanos en Argentina en sus localizaciones capitalina, del interior y del exterior y de la agrupación equis en tal localidad (Alonso, 2011). Ejemplo de imbricación: en el análisis del teatro santafesino de 1955 / 1979 se puede ver: 1) una temporalidad caracterizada por la creciente implicación estatal que atraviesa los gobiernos, 2) una temporalidad relativa a la vitalidad del campo que puede traducirse en un período de "auge" hasta c. 1966 y una posterior "decadencia", 3) una recurrencia de determinadas políticas marcada por las intervenciones militares y 4) una temporalidad que responde a la dinámica de las agrupaciones teatrales e incluso de las trayectorias personales (Alonso, 2018b).

b) Periodizaciones variables y secuencias sincopadas. Variaciones menores en los criterios de interpretación pueden fundamentar periodizaciones diversas y al mismo tiempo iluminar momentos específicos del despliegue temporal de un fenómeno o agente. Por ejemplo, se puede predicar una integración simbólica fuerte del movimiento por los derechos humanos en territorio argentino entre 1975-1977 y 2006, aproximadamente, momento en el cual su partición es evidente. Pero si se maneja un criterio más estricto que suponga una cierta unidad discursiva y un mayor grado de integración, el movimiento social podría identificarse como un agente colectivo plural pero al mismo tiempo unificado apenas entre 1977 y $1984-86$ (este tipo de doble periodización, extensa y acotada, está inspirada en el planteo de Guerreau -1984, cap. 6- respecto del feudalismo). Una variante de ese ejercicio es la identificación de distintas temporalidades de agentes o agencias específicas del movimiento social. En ese sentido la narrativa unificada sobre construcción del movimiento social puede mantenerse pero abrirse sus finales en función de distintas agrupaciones o localizaciones (este modelo está inspirado en Morsel, 2008, sobre los fines del feudalismo). Por fin, si se cotejan distintas localizaciones espaciales se puede apreciar que los procesos de movilización se producen de manera sincopada: por ejemplo, la participación e impacto de la movilización es distinta en el interior y el exterior del territorio nacional en la defensa de los derechos humanos a lo largo del tiempo; cuando la represión o las políticas de impunidad limitan las acciones de los agentes movilizadores al interior del territorio, crecen las acciones en el exterior.

c) Identificación de saltos y reversiones temporales. La revisión del tiempo lineal y progresivo supone la posibilidad de encontrar otro tipo de movimientos temporales. Ellos se aprecian por ejemplo en la lógica de relación hijos / madres en la movilización pro derechos humanos. Inicialmente los hijos son los desaparecidos buscados por sus madres; luego las Madres plantean la idea de que sus hijos "las parieron" a la lucha política -reversión temporal-; más tarde los hijos de los hijos comienzan a construir identidades en vínculo con la memoria de sus padres - movimiento hacia atrás en el tiempo-y la movilización de sus abuelas (las Madres) movimiento en paralelo- y por fin la constitución de H.I.J.O.S. los enlaza en la herencia de las luchas y forma un nuevo arco temporal (Alonso, 2014b). Esta dimensión se basa más en la experiencia del tiempo en tanto visión emic que en la distinción entre temporalidades y la periodización desde una perspectiva etic.

Con respecto a la construcción de la espacialidad en el proceso investigativo, mis trabajos tienen en general una encarnadura local. Eso se relaciona desde hace mucho tiempo con dos supuestos: 
a) la relación de la parte y el todo o de lo particular y lo general es siempre compleja, pero lo que no está en ningún lugar no existe (Santos, 1996). En consecuencia, deberíamos poder apreciar las relaciones de dominación y resistencia en situaciones localizadas aun cuando fueran parte de modos o formas extendidas;

b) mi dedicación a la investigación ha sido muy escasa a lo largo de los años en comparación con las actividades docentes, de gestión o administrativas, por lo cual la fijación en situaciones locales es también una opción razonable desde la perspectiva de su factibilidad. Eso, pese a que asumiendo algunos de los planteos de la teoría de los sistemas-mundo trato de pensar también en términos macrosociales -y pienso que esa misma teoría, en su combinación con las teorías de la estructuración, ofrece posibilidades de articular las escalas macro y micro (Taylor y Flint, 2002)-.

La cuestión de la definición de distintas escalas de análisis y su relación está en el centro de mi reflexión desde la época en la cual me dedicaba al impacto de los procesos de "glocalización" (Robertson, 2000). Siempre trabajé con la idea de una pluralidad de espacios: espacios diversos en función de su correspondencia con una u otra esfera de lo social, espacios distintos en los planos local-regionales, espacios articulados por redes, niveles espaciales diferentes desde lo local a lo mundial. Conviene aquí traer a colación la idea de Sewell, según la cual podemos decir que un espacio social existe realmente cuando hay agentes individuales y sociales que se desempeñan o "juegan” en ese nivel (Sewell, 2006). En ese sentido, el sistema mundial capitalista es un espacio muy real y para nada abstracto, en el que juegan agentes con capacidades globales.

Por otra parte, la definición de espacios diversos pero análogos o equivalentes me parece esencial para posibilitar la comparación, con criterios como los apuntados anteriormente (v. g. Alonso, 2010). He trabajado entonces reiteradamente el tema, tratando de distinguir y relacionar espacios como los del sistemamundo, el estado-nación, las regiones y las localidades y sus zonas de influencia en el estudio de procesos o acciones específicas (Alonso, 2015b).

\section{Rigurosidad y CREATIVIDAd (O MEJOR DiCHO SUS INTENTOS)}

Una de las cuestiones abordadas en el conversatorio aludido tenía que ver con las perspectivas y experiencias que permitían pensar la "rigurosidad" en las investigaciones, aunque quizás pueda plantearse que la rigurosidad consiste simplemente en no hacer trampa. A mi entender, es posible un conocimiento "objetivo" en el sentido de acuerdo "intersubjetivo" sobre la experiencia. Para eso se requiere tener en claro no sólo las formas mediante las cuales se puede llegar al conocimiento sobre lo social sino muy principalmente el carácter limitado, provisorio y hasta equívoco de nuestros conocimientos. Creo que incluso si nos mantuviéramos en el marco del objetivismo estaríamos condenados a admitir que todos nuestros esfuerzos por entender serán malentendidos, juicios erróneos y simplificaciones injustificadas, y que todo lo que podemos hacer al respecto es hacer frente a ese hecho y ser lo más honestos y críticos que podamos (véase v. g. Jarvie, 1974, p. 160).

No creo que el rigor disciplinar o científico sea cuestión de apego a un método determinado, sino a una actitud general de control sobre la propia práctica aún en un marco metodológico plural. Obviamente, eso está interrelacionado con la búsqueda de fuentes de distinta índole y la posibilidad de constante triangulación. Entonces las pautas de mi parte para una cierta rigurosidad podrían encontrarse en lo siguiente:

a) En primer término, una articulación explícita entre conceptos precisos y conceptos flotantes. Retornando a un problema planteado más arriba, podría admitirse que: 1 . Es conveniente ser riguroso en el recurso a los términos técnicos, sean categorías ordenadoras o conceptos descriptivos; 2. Pero los términos elegidos pueden a veces ser "flotantes", es decir, ser amplios y tener distintas posibilidades de articulación en un universo posible de sentidos; ${ }^{8}$ y 3 . El carácter de un concepto está dado por los entramados conceptuales de los cuales participa. La rigurosidad conceptual estaría dada más bien entonces en el recurso combinado de una terminología consagrada o más puntual, con categorías más difusas cuyo sentido puede variar de un texto a otro pero que en cada ocasión deben definirse explícitamente. 
b) En el plano de la articulación general entre investigación y presentación de resultados, hay que tener en claro las diferencias entre el método de investigación y el método de exposición (Marx, 2004, p. 19). En este sentido, me parece que la pretensión que han tenido muchos autores de presentar una exposición que seguiría el proceso de conocimiento refleja siempre una posibilidad posterior al proceso de investigación y es en parte inauténtica. En otras palabras, escribir como si quien lo hace fuera ignorante del resultado final es simplemente un artificio de discurso que puede caer en cierto impresionismo.

c) En cuanto a la posibilidad de enunciados fundados, creo importante sostener la idea de la prueba documental como base del conocimiento histórico. Eso no quita que en algunos momentos haya una posibilidad de especulación o inferencia lógica, pero eso es un recurso limitado que trata de complementar la inferencia documental y que no puede reemplazarla.

d) Correlativamente, en el plano de la escritura la rigurosidad estaría dada por un lado por el control de las ficciones de método -esto es, por la aplicación controlada de la imaginación y de las especulaciones contrafactuales- y por el otro por una forma de exposición que presente en todo momento la posibilidad de ser sometida a prueba e incluso negada. Creo conveniente ampliar en las narraciones explicativas el uso de los verbos en potencial, para no sostener afirmaciones sin sustento firme como si fueran verdades consagradas y al mismo tiempo sugerir la conveniencia de imaginar / investigar otras cuestiones.

El complemento de la rigurosidad fue, en la ocasión del conversatorio, la cuestión de la "creatividad" en el diseño y desarrollo del proceso de investigación. A ese respecto entiendo que el papel de la creatividad en la investigación histórica es muy amplio. No sé si llamarlo intuición o alejarme de esa palabra y referir simplemente al "olfato" que otorga la práctica de un oficio. Como sea, gran parte de las articulaciones que puedo postular para situaciones dadas o de los problemas que defino son emergentes de contextos muy poco orientados por la rigurosidad analítica y mayormente vinculados con la oportunidad de conectar temas diversos. Siguiendo una conocida máxima del recordado Ricardo Falcón, el mejor proyecto de investigación es el que se escribe luego de realizada la propia investigación. Ergo, la creatividad es indispensable para encarar los inicios de una investigación posible ante la incertidumbre sobre lo que vendrá.

Si la creatividad supone adoptar una actitud abierta hacia el conocimiento y los métodos para conseguirlo, me parece que es un recurso esencial y que muchas situaciones pueden ser ilustradas gracias al recurso a:

a) la analogía, encontrando similitudes en espacios o fenómenos muy diversos, para a partir de allí trabajar la diferencia;

b) la extrapolación conceptual, aplicando a un área un concepto desarrollado para otra área -inclusive produciendo variaciones de significado-; y

c) la trasposición metodológica, tratando de aplicar a un área enfoques, actitudes o técnicas desarrolladas respecto de otra área - por ejemplo, aplicando observaciones de Guerreau o Morsel sobre la periodización del feudalismo a un objeto definido para la historia del presente, como he sugerido antes-.

Aunque quizás esas tres estrategias no sean tan distintas o separables. En rigor todas se refieren a la posibilidad de transferir enfoques y conceptos de un área de conocimientos a otra, de una disciplina a otra, de un tiempo-espacio a otro, con todos los riesgos que eso conlleva.

\section{CONCLUSIÓN INCONCLUYENTE}

Probablemente este escrito un tanto compulsivo, que requeriría ampliaciones, referencias y ejemplos casi a cada línea, no sea una buena guía o ilustración para nadie. A las y los estudiantes de grado y posgrado en historia se les enseña sensatamente a tomar un par de autores de referencia, llenar sus textos de citas a pie de página y construir una tesis en la cual objetivos, hipótesis, fuentes, metodología y desarrollo sean congruentes. Pero en mi caso particular no puedo dejar de alentar (y admirar) a quienes me parece que tienen pensamientos arborescentes. Esto es, con raíces sólidas pero con ramas y gajos que se van abriendo sin terminar de cerrar 
nunca. Poco eficientes vistos los criterios productivistas, pero más sensibles a la comprensión del pasado y su articulación con las luchas del presente.

Las ciencias sociales y humanas no son paradigmáticas, no hay un único modelo de ciencia ni una teoría universalmente aceptada para nada, ni siquiera un lenguaje mínimamente unificado. Y está bien que así sea. No porque todo tenga el mismo valor $-\mathrm{y}$ claramente hay investigaciones útiles e inútiles, correctas e incorrectas, admirables y desastrosas-, sino porque nuestras propias labores académicas son prácticas semióticas desplegadas en entornos construidos, dependientes de múltiples variables en múltiples espacios y tiempos. Y siendo también lo social un campo de luchas de intereses y sentidos, no podemos esperar más que la coexistencia y choque de una pluralidad de historias (en el doble sentido de narraciones y de historiografías). A partir de aceptar el carácter siempre inacabado y conflictivo del conocimiento sobre lo social, podríamos entonces comenzar a discutir qué usos (sociales) tendría la historiografía.

\section{REFERENCIAS}

Alonso, L. y Vega, N. (2000). La invención de un lugar. Itinerarios culturales de una localidad santafesina entre la colonización y la globalización. Rosario: Subsecretaría de Cultura de la Provincia de Santa Fe.

Alonso, L. (1999). Modos de control y conflictos culturales en la España de los Austrias: discursos sobre una máquina ventrílocua. Anuario de la Escuela de Historia de la Universidad Nacional de Rosario, 18, $49-62$.

Alonso, L. (2010). Defensa de los derechos humanos frente a las dictaduras regresivas: los casos de Argentina y Uruguay en perspectiva comparada. Studia Historica / Historia Contemporánea, 28, 23-50.

Alonso, L. (2011). Luchas en plazas vacias de sueños. Movimiento de derechos humanos, orden local y acción antisistémica en Santa Fe. Rosario: Prohistoria.

Alonso, L. (2014a). Las violencias de Estado durante la última dictadura argentina: problemas de definición y análisis socio-histórico. En W Ansaldi y V. Giordano (coords.), América Latina. Tiempos de violencias (pp. 191-213). Buenos Aires: Ariel.

Alonso, L. (2014b). “Abuelas / Nietos", "Hijos" y "Madres". En A. Adelstein y G. Vommaro (coords. y eds.), Diccionario del léxico corriente de la política argentina. Palabras en democracia. 1983-2013 (pp. 29-32, 201-203 y 230-233). Los Polvorines: Universidad Nacional de General Sarmiento.

Alonso, L. (2015a). Retorno de la totalización y método historiográfico. En Actas de las Iras. Jornadas Nacionales de Historiografía (pp. 174-195). Río Cuarto: Universidad Nacional de Río Cuarto. Recuperado de https://www.u nrc.edu.ar/unrc/comunicacion/editorial/librosDig.php.

Alonso, L. (2015b). Redes y dimensiones espaciales en la movilización por los derechos humanos en Argentina. Avances del Cesor, 12(12), 117-139.

Alonso, L. (2017). Teatro en transición. Dramaturgia, política y relaciones sociales en Santa Fe (Argentina), entre la última dictadura y la transición democrática. RBBA - Revista Binacional Brasil Argentina, 6(2), 116-147. https ://doi.org/10.22481/rbba.v6i2.3666

Alonso, L. (2018a). La "Historia Reciente” argentina como forma de Historia actual: emergencia, logros, ¿bloqueos?. Historiografias, revista de historia y teoria, 15, 73-92. https://doi.org/10.26754.

Alonso, L. (2018b). Trayectos y articulaciones socio-políticas en el teatro independiente santafesino, c. 1966-1984. En IX Jornadas de Trabajo sobre Historia Reciente. Universidad Nacional de Córdoba, Córdoba.

Alonso, L. (2019a). La cultura y sus proyecciones políticas durante la transición a la democracia en Argentina. En C. Molinero y P. Ysàs (eds.), Transiciones. Estudios sobre Europa del Sur y América Latina (pp. 82-103). Madrid: Los Libros de la Catarata.

Alonso, L. (2019b). Clases sociales y movilización pro derechos humanos en la historia Argentina reciente. Diálogos, 23(3), 154-175. http://dx.doi.org/10.4025.dialogos.v23i3.49963. 
Alonso, L. (2019c). Organismos, movimientos, campos, espacios, escenarios. Un retorno a los debates sobre la definición de las luchas por los derechos humanos. En XVII Jornadas Interescuelas / Departamentos de Historia. Universidad Nacional de Catamarca, San Fernando del Valle de Catamarca.

Baxandall, M. (2010). Giotto y los oradores. La visión de la pintura en los humanistas italianos y el descubrimiento de la composición pictórica, 1350-1450. Madrid: Visor.

Bourdieu, P. (2007). El sentido práctico. Buenos Aires: Siglo XXI.

Engels, F. (2000). Del socialismo utópico al socialismo cientifico. En Marxists Internet Archive. Recuperado de https:// www.marxists.org/espanol/m-e/1880s/dsusc/index.htm.

Foucault, M. (1994). Microfisica del poder. Buenos Aires: Planeta-Agostini.

Foucault, M. (2007). Elpoder psiquiátrico. Curso en el Collège de France (1973-1974). Buenos Aires: Fondo de Cultura Económica,

Giddens, A. (1995). La constitución de la sociedad. Bases para la teoría de la estructuración. Buenos Aires: Amorrortu.

Ginzburg, C. (1989). Morelli, Freud y Sherlock Holmes: indicios y método científico. En U. Eco y T. A. Sebeok (eds.), El signo de los tres. Dupin, Holmes, Peirce (pp. 116-163). Barcelona: Lumen.

Ginzburg, C. (2007). Reflexiones sobre una hipótesis: el paradigma indiciario, veinticinco años después. Contrahistorias, 7, 7-16.

Godelier, M. (1976). Racionalidad e irracionalidad en economía. México: Siglo XXI.

Grendi, E. (2004). Paradojas de la historia contemporánea. Contrahistorias, 2, 55-62.

Grüner, E. (2006). Lecturas culpables. Marx(ismos) y la praxis del conocimiento. En A. A. Borón, J. Amadeo y S. González (comps.), La teoría marxista hoy. Problemas y perspectivas (pp. 105-147). Buenos Aires: CLACSO.

Guerreau, A. (1984). El feudalismo. Un horizonte teórico. Barcelona: Crítica.

Harris, M. (1998). Antropología cultural. Madrid: Alianza.

Hung, H. (2019). El capitalismo, la hegemonía y los imperios a escala global. En C. Benzecry, I. A. Reed y M. Krause (comps.), La teoría social, ahora (pp. 127-154). Buenos Aires: Siglo XXI.

Jarvie, I. C. (1974). Comprensión y explicación en sociología y en antropología social. En R. Borger y F. Cioffi (comps.), La explicación en las ciencias de la conducta (pp. 159-207). Madrid: Alianza.

Kracauer, S. (2010). Historia. Las últimas cosas antes de las últimas. Buenos Aires: Las Cuarenta.

Lane Fox, R. (2009). Héroes viajeros. Los griegos y sus mitos. Barcelona: Crítica.

Marx, K. (1972). El método de la economía política. En Introducción general a la crítica de la economía política / 1857 (pp. 20-30). Córdoba: Pasado y Presente.

Marx, K. (1993). Tesis sobre Feuerbach. En La cuestión judia y otros escritos (pp. 229-232). Barcelona: Planeta / Agostini.

Marx, K. (2004). Epílogo a la Segunda Edición. En El Capital. Crítica de la Economía Política. Libro Primero. El proceso de producción del capital, vol. 1 (pp. 11-20). Buenos Aires: Siglo XXI.

Marx, K. (2014). Carta a Arnold Ruge de septiembre de 1843. En Marxists Internet Archive. Recuperado de https:// www.marxists.org/espanol/m-e/cartas/m09-43.htm.

Morsel, J. (2008). La aristocracia medieval, El dominio social en Occidente (siglos V-XV). Valencia: Universitat de València.

Negri, A. (2001). Contrapoder. En A. Negri et al., Contrapoder. Una introducción. Buenos Aires: Ediciones De mano en mano.

Portelli, A. (2004). El uso de la entrevista en la historia oral. Anuario de la Escuela de Historia de la Universidad Nacional de Rosario, 20, 35-48.

Ricoeur, P. (1991). Ideologia y utopia. Barcelona: Gedisa.

Robertson, R. (2000). Glocalización: tiempo-espacio y homogeneidad-heterogeneidad. Zona Abierta, 92/93, 213-242.

Santos, M. (1996). De la totalidad al lugar. Barcelona: Oikos. 
Sewell Jr., W. H. (2005). Logics of History. Social Theory and Social Transformation. Chicago y Londres: The University of Chicago Press.

Sewell Jr., W. H. (2006). Por una reformulación de lo social. Ayer, 62, 51-72.

Taylor, P. y Flint, C. (2002). Geografía politica. Economí-mundo, estado-nación y localidad (2da. edición corregida y aumentada). Madrid: Trama.

Thompson, E. P. (1981). Miseria de la teoría. Barcelona: Crítica.

Thompson, E. P. (2000). Historia y antropología. En Agenda para una historia radical (pp. 15-43). Barcelona: Crítica.

Thompson, J. B. (1987). Lenguaje e ideología. Zona Abierta, 41/42, 159-181.

Tilly, Ch. (1991). Grandes estructuras, procesos amplios, comparaciones enormes. Madrid: Alianza.

Tilly, Ch. (2000). La desigualdad persistente. Buenos Aires: Manantial.

Wallerstein, I. (1998). Impensar las ciencias sociales. Limites de los paradigmas decimonónicos. México: Siglo XXI.

Wallerstein, I. (2008). Historia y dilemas de los movimientos antisistémicos. México: Contrahistorias.

Zemon Davis, N. (1984). El regreso de Martin Guerre. Barcelona: Bosch.

Zemon Davis, N. (2013). El historiador y los usos literarios. Historia y Justicia, 1, 1-7.

\section{Notas}

1 Podríamos decir, con Pierre Bourdieu, que es a partir de esa noción de Marx que podemos pensar al sujeto “...en «la actividad real como tal», es decir, en la relación práctica con el mundo” (Bourdieu, 2007, p. 85). De igual manera el estructuracionismo en sí y toda posibilidad de superación de la dicotomía acción/estructura puede presentarse como una profundización de la reflexión sobre la famosa frase de Marx en El 18 Brumario de Luis Bonaparte según la cual los seres humanos hacen la historia, pero en condiciones que no conocen ni controlan (Giddens, 1995, p. 22).

2 La concepción del materialismo histórico como una tradición y no como una teoría o cuerpo de doctrina acabados, en Thompson, 1981 -a quien, por lo demás, se acusaba de "culturalismo"-. La del método de Marx como uno y múltiple, tendiente a la indivisión disciplinar, en Godelier, 1976.

3 "Me sucede con frecuencia citar frases, conceptos, textos de Marx, pero sin sentirme obligado a adjuntar la pequeña pieza identificatoria que consiste en hacer una cita de Marx, en poner cuidadosamente la referencia a pie de página y acompañar la cita de una reflexión elogiosa... Es imposible hacer historia actualmente sin utilizar una serie interminable de conceptos ligados directa o indirectamente al pensamiento de Marx y sin situarse en un horizonte que ha sido descrito y definido por Marx. En caso límite se podría uno preguntar qué diferencia podría haber entre ser historiador y ser marxista." (Foucault, 1994, p. 100).

4 "Es mucho más normal y frecuente que sean los historiadores medievalistas y modernistas los que escogen los temas diferentes, los que abren nuevas canteras de investigación, es decir, los que descubren nuevas fuentes y nuevos sujetos de estudio, los que verifican hipótesis y preguntas nuevas, y los que renuevan a veces, a partir de la inspiración de las disciplinas hermanas, el aparato conceptual y las interpretaciones" (Grendi, 2004, p. 57).

5 Para mis propias observaciones, dudas y propuestas respecto de la "historia reciente", la "historia del presente" o la "historia actual" véase Alonso, 2018a.

6 He tratado el retorno de la totalización en la historiografía (Alonso, 2015a), lo que no supone la anulación de las diferencias o individualizaciones sino precisamente un momento de captación global que luego es desmontado, actualizado y vuelto a postular.

7 Personaje de la serie televisiva “Doctor House” o “House M. D." de la empresa Fox, que se emitió entre 2004 y 2012 y cuyo protagonista principal era encarnado por el actor Hugh Laurie. La leyenda "everybody lies", junto con otras frases destacadas que caracterizaban al personaje, fue usada para la producción de merchandising o la realización de memes (en el doble sentido teórico y comunicacional de la palabra). Ese fue también el título del primer episodio de la serie.

8 Tomo la idea de "concepto flotante" de Bob Jessop para hacer alusión a categorías lábiles, que tienen contornos difusos y que superponen o imbrican sentidos. Un desarrollo particularizado de ello en Alonso, 2019c. 